\title{
A PSICOTERAPIA COMO COMPETÊNCIA ACRESCIDA AVANÇADA EM ENFERMAGEM
}

$\mid$ Helena Quaresma ${ }^{1} \mid$

O reconhecimento da Psicoterapia como competência acrescida avançada foi alcançado com a publicação do Regulamento n. ${ }^{o} 387 / 2019$, concretizando um objetivo traçado anteriormente por um grupo de enfermeiros especialistas em Enfermagem de Saúde Mental e Psiquiátrica. Um pouco de história torna mais claro o percurso percorrido. Sobre esta matéria é importante referir o documento elaborado sobre as "Competências dos Profissionais de Saúde Mental nos Cuidados Continuados Integrados de Saúde Mental" pela Subcomissão dos Cuidados Integrados de Saúde Mental, criada pelo Conselho Nacional de Saúde Mental, que considera a psicoterapia como uma "competência partilhada relativa aos clientes (...) realizada por técnicos de Saúde Mental com formação pós-graduada numa das Sociedades de Psicoterapia reconhecidas para o efeito em Portugal" (Conselho Nacional de Saúde Mental, 2015). Este grupo de trabalho integrou representantes da Ordem dos Enfermeiros, Ordem dos Psicólogos e Ordem dos Médicos, tendo sido alcançado o consenso que, para estas três profissões de saúde, a Psicoterapia seja reconhecida de acordo com o sistema de reconhecimento profissional em vigor em cada Ordem.

Este entendimento de que o ato psicoterapêutico não é pertença exclusiva de qualquer categoria profissional fundamenta-se, entre outros documentos, na Declaração de Strasbourg sobre Psicoterapia (de 1990), assinada por 14 países, sendo este ponto de vista corroborado pela Federação Portuguesa de Psicoterapia (FEPPSI) enquanto organização representativa de 17 Associações e outras Pessoas Coletivas de direito privado na área da Psicoterapia em Portugal.

Podemos então concluir que o título de psicoterapeuta se aplica a todos os profissionais detentores de formação pós-graduada especializada em Psicoterapia (formação independente da Medicina, Psicologia, Enfermagem ou outras áreas académicas), dentro de um dos diferentes modelos e métodos psicoterapêuticos, que respeitem os critérios mínimos estabelecidos pela FEPPSI, que enquadre todos os princípios emanados pela European Association of Psychoterapy (EAP) nos diferentes componentes de formação nesta área da saúde: formação teórico-prática, supervisão e desenvolvimento pessoal com supervisão da prática clínica.

Impõe-se clarificar o termo psicoterapia. Psicoterapia abarca vários modelos teóricos e de intervenção, que vão desde a palavra à intervenção psicocorporal, num total de mais de 20 modelos que reúnem diversas perspetivas sobre o tratamento não farmacológico. É o processo mediado por um profissional especializado, como forma de tratamento de estados de sofrimento e perturbações psicossociais, psicossomáticas e comportamentais através de uma relação psicoterapêutica diferenciada, abrangente, consciente e planeada, recorrendo a técnicas não farmacológicas, alicerçada em diferentes modelos e métodos psicoterapêuticos, com o propósito de promover a mudança, o desenvolvimento e a saúde das pessoas que a ela recorrem (Regulamento n. ${ }^{\circ} 387 / 2019$ ).

Segundo os dados disponibilizados pela FEPPSI, em Portugal, ao longo do tempo receberam formação e exercem legitimamente a Psicoterapia - reconhecidos pelas suas sociedades, associações ou escolas - médicos, psicólogos, enfermeiros, filósofos, sociólogos, assistentes sociais, pedagogos e outros provenientes das áreas das ciências exatas, ciências humanas e sociais, e artes. Tornava-se assim necessário enquadrar no exercício profissional de Enfermagem a psicoterapia como competência acrescida avançada. Centremo-nos então nos documentos normativos, enquadradores desta matéria, emanados pela Ordem dos Enfermeiros. À luz do Regulamento Geral das Áreas de Competência Acrescida (Regulamento n. ${ }^{\circ}$ 556/2017) estas emergem da complexificação permanente dos conhecimentos e das práticas que ao longo do seu percurso profissional o enfermeiro vai adquirindo, potenciando progressivamente novos campos de atuação do exercício profissional autónomo do enfermeiro e do enfermeiro especialista.

No sentido de abranger diferentes níveis de complexidade das intervenções de Enfermagem são instituídas as Competências acrescidas Diferenciadas e as Competências acrescidas Avançadas, onde se insere a Psicoterapia.

1 Enfermeira especialista em Enfermagem de Saúde Mental e Psiquiátrica; Doutora em Enfermagem e Saúde; Presidente da Mesa do Colégio da Especialidade de Enfermagem de Saúde Mental e Psiquiátrica da Ordem dos Enfermeiros; Professora Coordenadora na Escola Superior de Enfermagem de Coimbra, Portugal, quaresma@esenfc.pt

Citação: Quaresma, H. (2019). A psicoterapia como competência acrescida avançada em enfermagem. Revista Portuguesa de Enfermagem de Saúde Mental (21), 05-08. 
Ainda sobre este conceito, o regulamento acima referido, no art. $^{\circ} 2$, alínea b), define competências acrescidas avançadas como sendo "conhecimentos, habilidades e atitudes que dão resposta às necessidades, nos diversos domínios de intervenção, acrescentando, às competências do enfermeiro especialista, a perícia fruto da complexidade permanente dos conhecimentos, práticas e contextos numa área de intervenção avançada, potenciando a promoção da qualidade da intervenção do enfermeiro especialista" (Regulamento n. ${ }^{0}$ 556/2017, p. 23636).

Por reconhecer a elevada especificidade e relevância do exercício da Enfermagem em Psicoterapia, a Ordem

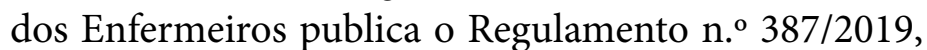
onde define o perfil do enfermeiro psicoterapeuta e os termos de Certificação da Competência Acrescida Avançada em Psicoterapia no âmbito do Exercício Profissional de Enfermagem.

Então, quem pode requerer a certificação individual da competência acrescida avançada em psicoterapia?

Os enfermeiros com título profissional de enfermeiro especialista, na área da especialidade em Enfermagem de Saúde Mental e Psiquiátrica ou em Enfermagem Comunitária, atribuído pela Ordem, com exercício profissional efetivo de Enfermagem especializada de pelo menos três anos, e ser detentor de formação habilitante especializada em Psicoterapia realizada em entidade científica membro da Federação Portuguesa de Psicoterapia (FEPPSI) ou em entidade científica reconhecida por congénere internacional, que cumpra os critérios mínimos de formação de psicoterapeutas e tenha beneficiado de acreditação pela Ordem (art. ${ }^{\circ}$ 7, Regulamento n. ${ }^{\circ}$ 556/2019). O programa formativo para a atribuição da Competência Acrescida Avançada em Psicoterapia constitui-se como um referencial orientador da formação requerida, devendo integrar as áreas temáticas inscritas no Anexo II do Regulamento acima mencionado e cumprir um mínimo de 400 horas de formação teórico-prática, $250 \mathrm{~h}$ de trabalho clínico sob supervisão, 150 horas de supervisão de casos de Psicoterapia e 175 horas de Psicoterapia ou desenvolvimento pessoal. O desempenho das competências inerentes às funções de Psicoterapia, no âmbito do exercício profissional de Enfermagem compete, exclusivamente, aos detentores de título de Enfermeiro Especialista nas áreas de Enfermagem de Saúde Mental e Psiquiátrica e de Enfermagem Comunitária, com atribuição da Competência Acrescida Avançada em Psicoterapia, devidamente inscrita na cédula profissional.
O perfil do Enfermeiro com Competência Acrescida Avançada em Psicoterapia integra, cumulativamente, as competências do Enfermeiro Especialista comuns e específicas, previamente adquiridas, com o desempenho das competências inerentes às funções de Psicoterapeuta. O enfermeiro psicoterapeuta "detém um conhecimento concreto e pensamento sistematizado, no domínio da disciplina, da profissão e da Psicoterapia, com competência efetiva e demonstrada do exercício profissional nesta área, e que intervém, através de uma relação psicoterapêutica diferenciada, consciente e planeada, com a pessoa/família/grupo; promove a mudança, o desenvolvimento e a saúde da pessoa que a ele se dirige, recorrendo aos diferentes modelos e métodos psicoterapêuticos. Desenvolve uma prática profissional, ética e legal, agindo de acordo com as normas legais, os princípios Éticos e a Deontologia Profissional, assegurando um exercício em Psicoterapia através de um processo de gestão de cuidados específicos, dinâmico e integral; formulando o contrato terapêutico e estabelecendo a relação psicoterapêutica ajustados à especificidade da situação; adotando as técnicas e as intervenções psicoterapêuticas adequadas; reconhecendo a importância da supervisão e intervisão no desenvolvimento da sua prática” (Regulamento n. ${ }^{\circ} 387 / 2019$, p. 13402).

A comparação entre as competências do psicoterapeuta, The Core Competencies of a European Psychotherapist, estabelecidas em 2013 pela European Association of Psychotherapy (EAP), as competências comuns do Enfermeiro Especialista (Regulamento n. ${ }^{\circ}$ 122/2011) e as do enfermeiro especialista em Enfermagem de Saúde Mental e Psiquiátrica põe em evidência uma concordância em matéria dos domínios da respetiva responsabilidade profissional, da melhoria contínua da qualidade da prestação de cuidados de saúde, da administração e gestão dos cuidados de saúde, e do desenvolvimento das aprendizagens profissionais. Trata-se por isso não de uma sobreposição de competências, mas de uma complementaridade de domínios, uma vez que que as competências comuns do Enfermeiro Especialista e as competências do Psicoterapeuta naqueles domínios se expressam diferentemente fruto das diferenças entre os respetivos contextos de exercício profissional e da articulação com o restante elenco de competências de cada um. Já no plano das competências específicas do Enfermeiro Especialista em Enfermagem de Saúde Mental (Regulamento n. ${ }^{\circ}$ 515/2018), em particular nas que se referem à detenção de um elevado conhecimento de si e à prestação de cuidados de âmbito psicoterapêutico, 
socioterapêutico, psicossocial e psicoeducacional, as competências que a EAP estabelece para o Psicoterapeuta excedem as do Enfermeiro Especialista em Enfermagem de Saúde Mental, partindo delas mas acrescendo profundidade e complexidade, como se pode constatar no documento The Core Competencies of a European Psychotherapist (EAP, 2013).

A formação de Psicoterapia, adicional à formação prévia de Enfermeiro de Cuidados Gerais e de Enfermeiro Especialista em Enfermagem de Saúde Mental e Psiquiátrica, cria um "background" de compreensibilidade holística que permite que um Psicoterapeuta com esta matriz profissional esteja particularmente bem preparado para responder às necessidades em saúde mental dos indivíduos, famílias e grupos.

A este propósito, importa referir ainda que são já vários os Enfermeiros Especialistas em Enfermagem de Saúde Mental (mas também de Enfermagem Comunitária) que fizeram formação como Psicoterapeuta numa das Associações, Sociedades Científicas nacionais ou Escolas acreditadas internacionalmente para o efeito. Neste sentido, a consideração da Psicoterapia como competência acrescida avançada não apenas legitima profissionalmente e interpares essa formação e desenvolvimento de competências profissionais, como oferece à população maior regulação, segurança e qualidade nos cuidados prestados.

Esta matéria assume importância acrescida pois estamos perante a confirmação crescente da magnitude dos problemas de saúde mental, com a estimativa de que as perturbações depressivas serão a primeira causa mundial de carga global de doença (Organização Mundial da Saúde [OMS], 2013), em que na Europa as doenças mentais apresentam uma elevada prevalência e representam uma carga significativa para os indivíduos e para a sociedade, representando $22 \%$ da carga das incapacidades, medida em anos vividos com incapacidade.

Os dados relativos a Portugal, extraídos do primeiro Estudo Epidemiológico Nacional de Saúde Mental (Almeida e Xavier, 2013), realizado no âmbito do World Mental Health Survey Initiative, de 2013, revelam que as perturbações mentais comuns apresentam valores preocupantes: $22,9 \%$ de prevalência anual, com predomínio para as perturbações da ansiedade $(16,5 \%)$ e do humor (7,9\%). Dos 34 países que integraram o survey da OMS, Portugal teve a quarta mais elevada taxa de prevalência anual.

Acrescenta-se, ainda, que o relatório da ERS (Entidade Reguladora da Saúde, 2015) alerta para o consumo de psicofármacos, nomeadamente de benzodiazepinas, que apresenta níveis quase duplos em comparação com a média dos restantes países europeus, sugerindo que a prescrição é uma opção terapêutica muito frequente no nosso país na abordagem das perturbações ansiosas e depressivas, o que eventualmente poderá ser motivado pela indisponibilidade de propostas não farmacológicas alternativas e mais efetivas.

Face à necessidade de adequar as respostas dos países às necessidades crescentes das populações em matéria de saúde mental, a Organização Mundial de Saúde, de entre um conjunto de recomendações produzidas, aponta claramente, desde o virar do milénio (OMS, 2001), a necessidade de proporcionar atenção à comunidade, preparar recursos humanos e incrementar a investigação em saúde mental. Sendo que em matéria de tratamento das perturbações mentais e comportamentais se mantém a necessidade de "uma combinação equilibrada de três ingredientes fundamentais: "medicação (ou farmacoterapia), psicoterapia e reabilitação psicossocial” (p. 59), defende que a psicoterapia se considere um recurso terapêutico acessível e equilibradamente articulável com a farmacoterapia e a reabilitação psicossocial.

A psicoterapia integrada no processo de cuidados é reconhecida como uma mais-valia terapêutica, frequentemente de primeira linha, capaz de assegurar uma atempada e especializada intervenção na área da saúde mental, com a obtenção de ganhos em saúde, por proporcionar um suporte efetivo e integral à pessoa, em qualquer fase do ciclo vital e em qualquer etapa do ciclo familiar. Por tudo isto, estamos certos que a Psicoterapia como Competência Acrescida Avançada em Enfermagem responde às necessidades dos cidadãos em saúde mental e em particular em cuidados de enfermagem especializados.

\section{REFERÊNCIAS BIBLIOGRÁFICAS}

Almeida, J. M. C., e Xavier, M. (2013). Estudo epidemiológico nacional de saúde mental: $1^{\circ}$ relatório. Lisboa: Faculdade de Ciências Médicas, Universidade Nova de Lisboa.

Conselho Nacional de Saúde Mental. (2015). Competências dos profissionais de saúde mental nos cuidados continuados integrados de saúde mental. Lisboa: Conselho Nacional de Saúde Mental.

Entidade Reguladora da Saúde. (2015). Acesso e qualidade nos cuidados de saúde mental. Porto: Entidade Reguladora da Saúde. 
Organização Mundial da Saúde. (2001). Relatório sobre a saúde no mundo. Saúde mental: Nova concepção. Genebra: Organização Mundial da Saúde.

Organização Mundial da Saúde. (2013). Mental health action plan 2013-2020. Genebra: Organização Mundial da Saúde.
Regulamento n. ${ }^{o}$ 122/2011 (2011). D.R. 2a Série. N. ${ }^{\text {3 } 35,}$ 8648-8653.

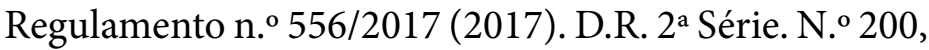
23636-23638.

Regulamento n. ${ }^{\circ}$ 515/2018 (2018). D.R. 2a Série. N. ${ }^{\circ} 151$, 21427-21430.

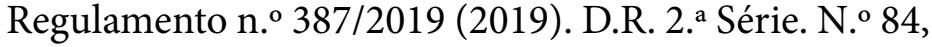
13401-13405.
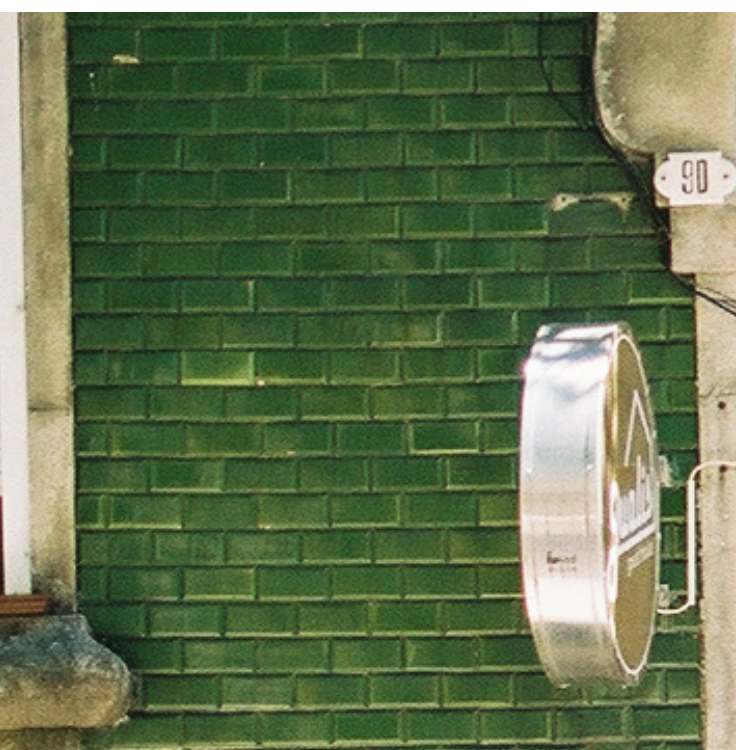

패피민.
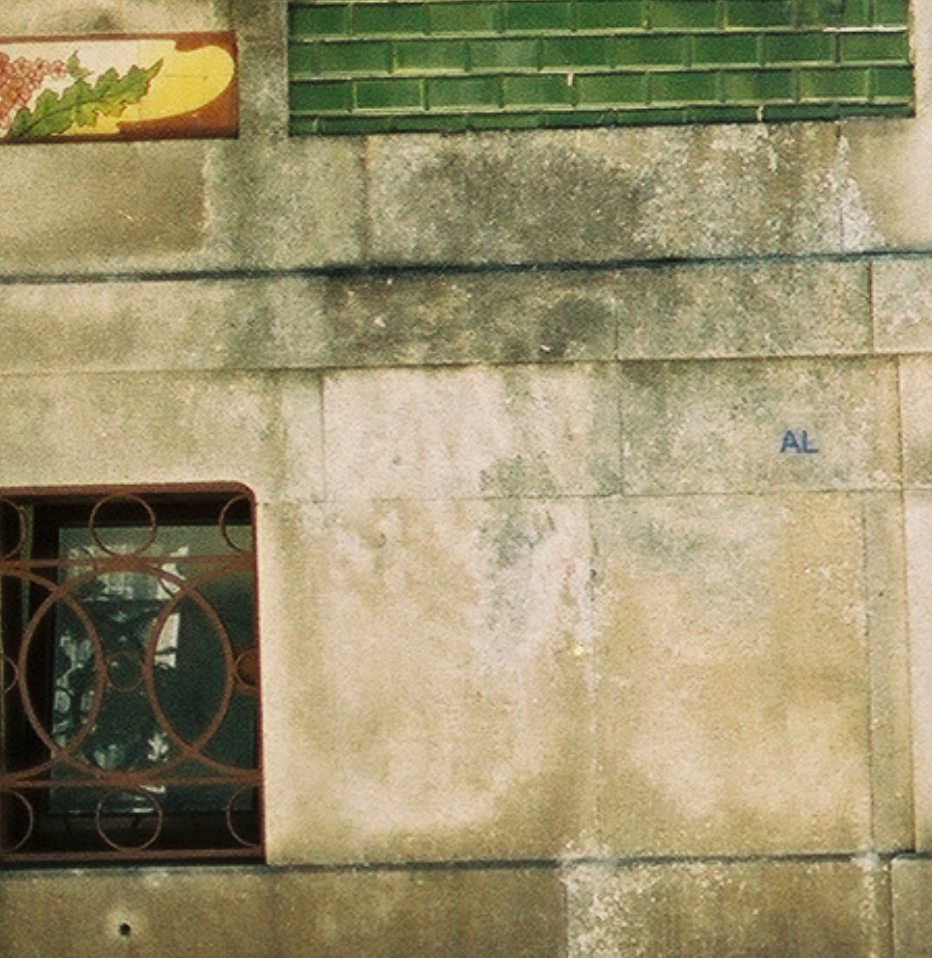

$\frac{3}{42} 45$
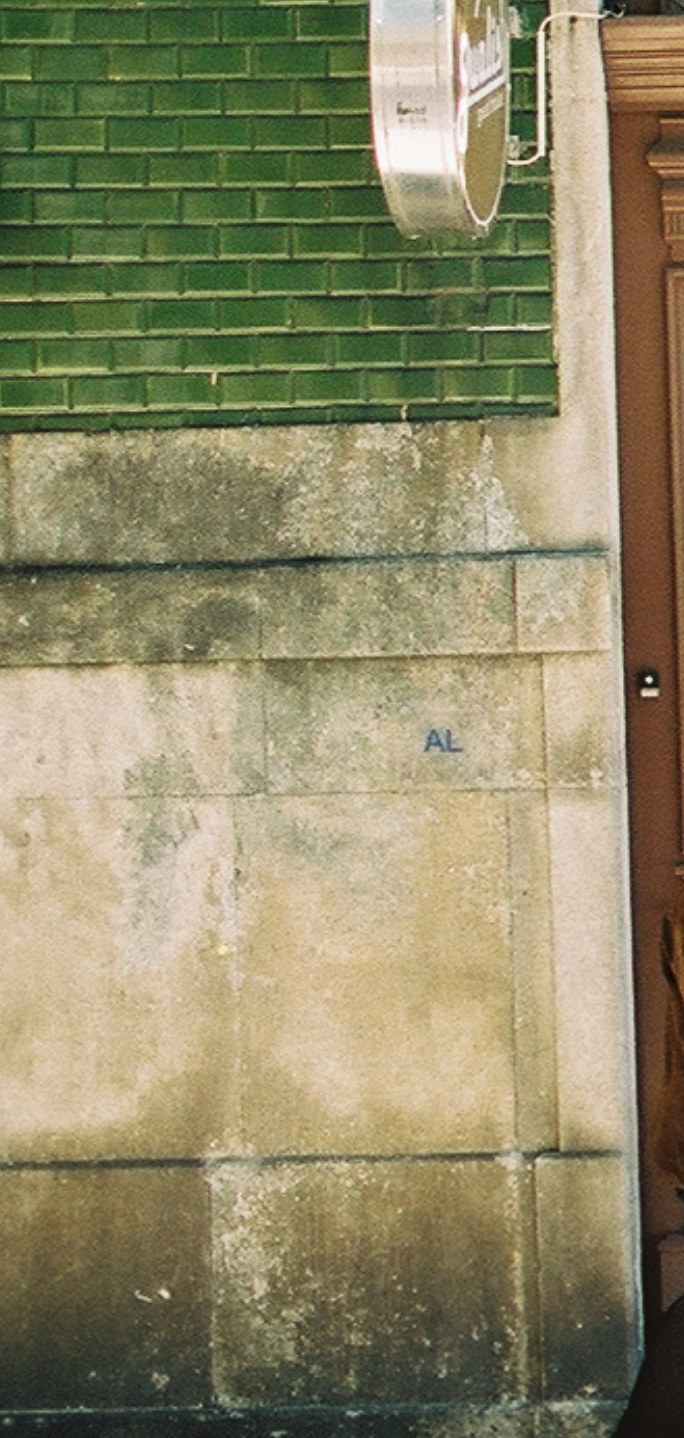